\title{
DESIGNAÇÃO DA ESPÉCIE-TIPO DO GÊNERO CARMINDA EBERT \& DIAS (LEPIDOPTERA, NYMPHALIDAE, SATYRINAE)
}

\section{Manoel Martins Dias ${ }^{1}$}

Carminda Ebert \& Dias 1997: 284 inclui três espécies: C. paeon (Godart, 1824), C. griseldis (Weymer, 1911) e C. umuarama Ebert \& Dias, 1997.

Na publicação original deste gênero, não foi designada a espécie-tipo.

Conforme o Código Internacional de Nomenclatura Zoológica (Artigos 42b, 67a e 69a), designo Satyrus paeon Godart, 1824: 490, como espécie-tipo do gênero Carminda.

\section{REFERÊNCIAS BIBLIOGRÁFICAS}

EBERT, H. \& M.M. Dias. 1997. Novos gênero e espécie de Satyrinae (Lepidoptera, Nymphalidae) do sudeste brasileiro. Revta bras. Zool. 14 (2): 283-298. GodART, J.B. 1819-(1824). Papillons. In: J.B. GodART \& P. LATREILle. Encyclopédie méthodique 9 . Paris, $828 \mathrm{p}$.

Recebido em 27.XI.1998; aceito em 04.XII.1998.

1) Departamento de Ecologia e Biologia Evolutiva, Universidade Federal de São Carlos. Caixa Postal 676, 13565-905 São Carlos, São Paulo, Brasil. 